previous reports ${ }^{2-4}$ that delayed and reduced secretion of progesterone occurs in a large proportion of women with minimal endometriosis. This abnormality persists after suppression of ovarian function for six months (unpublished findings). It may be, therefore, that this functional abnormality is of primary importance in the pathogenesis of infertility in this group of women and that it could in itself influence the development of ectopic endometrial tissue rather than being a secondary or associated factor.

Accordingly, it would seem reasonable to emphasise the need for careful endocrine assessment of these women, including luteal phase progesterone assays, before labelling their infertility as unexplained. Any abnormality of luteal function may then be identified and necessary treatment started. In these circumstances we would suggest that a biphasic basal body temperature, which does not confirm normal luteal function $^{5}$ and is a poor measure for timing ovulation, as the Sheffield workers have shown, is a somewhat inadequate assessment on which to base a diagnosis of unexplained infertility.

Finally, we would question whether the trial was really double blind. Treatment with gestrinone will cause significant menstrual disturbance, if not amenorrhoea, in most patients, whereas placebo will not. ${ }^{6}$ It may therefore be more appropriate to conduct comparative studies of different treatment modalities rather than comparing treatment with placebo.

K BANCROFT C A Vaughan Williams M ELSTEIN

University of Manchester,

Manchester M20 8LR

1 Williams CAV, Makarand C, Oak K, Elstein M. Cyclical gonadotrophin and progesterone secretion in women with minimal endometriosis. Clinical Repr and Fert 1986;4:259-68.

2 Brosens IA, Koninckx PR, Corveleyn PA. A study of plasma progesterone, oestradiol-17B, prolactin luteinising hormone progesterone, oestradiol-17, prolactin luteinising hormone levels and the luteal phase appearance of the ovaries in patients with endometriosis

3 Cheesman KL, Ben-Nun I, Chatterton RT, Cohen MR. Relationship of luteinising hormone, pregnanediol-3-glucuronide and oestriol-17-glucuronide in urine of infertile women with endometriosis. Fertil Steril 1982;38:542-8.

4 Cheesman KL, Cheesman SD, Chatterton RT, Cohen MR. Alterations in progesterone metabolism and luteal function in infertile women with endometriosis. Fertil Steril 1983;40: 590-5.

5 Jones GS. The luteal phase defect. Fertil Steril 1976;27:351-6.

6 Robyn C, Delogne-Desnoeck J, Bordeaux P, Capinschi G. Endocrine effects of gestrinone. In: Raynaud JP, ed. Medical management of endometriosis. New York: Raven Press, 1984.

\section{General practice consultations}

SIR,-Dr K B Thomas's clinical trial of the therapeutic influence of consultation style ( 9 May, p 1200) has such important implications that it is unfortunate that it is undermined by serious flaws. The most serious is in the design of the study, which contained a possible bias in the responses given to the postal questionnaire. Patients told that they would get better (positive consultations) may have been reluctant to contradict the doctor (the questionnaire was sent from the practice and would thus be associated with it); patients who had negative consultations would be less inhibited to admit that they were still unwell. What was measured was the patients' reluctance to deny cure, not the rate of cure.

Another source of possible bias lies in the comparability of the two groups. We are not told whether the two groups were equally distributed in their choice of usual doctor. Had the negative consultation group contained, by chance, more patients used to seeing a positive doctor then their lower rates for satisfaction and self reported cure might reflect expectation based on experience rather than some fixed characteristic of all patients.

$\mathrm{Dr}$ Thomas makes unsubstantiated conclusions about patient satisfaction as the reported differences were not significant, and even if they had been significant the conclusions would be irrelevant to clinical practice as the negative consultation chosen in this study does not reflect real shared consultation styles. Telling a patient "I cannot say exactly what the matter is but I am certain that it is not serious and what is more it will get better on its own" is a more accurate example of an honest consultation. It does not deserve to be castigated as negative.

\section{K HOPAYIAN}

Leiston,

Suffolk IP16 4ES

AUTHOR'S REPLY,-Dr Hopayian suggests that some patients treated positively felt obliged to say that they were well when in fact they were not. If this was so I would have expected an increase in the rates of return of those patients to see a doctor and a decrease in the rates of return to see me rather than another doctor compared with rates in the patients treated negatively. These changes did not, however, occur

The point of my investigation was that what is said by the doctor in the consultation may influence the satisfaction and the recovery of the patient. Dr Hopayian's suggestion that patients treated negatively who are used to seeing positive doctors have lower rates of satisfaction and recovery from illness surely supports the premise of the investigation. In any case, I showed that patients who chose to see me and who therefore presumably had some experience of my consulting style did very little better, and not significantly better, than those who did not choose to see me. I cannot help wondering how an anxious patient would view Dr Hopayian's statement that her illness is not serious and that it will get better on its own when she has just heard him admit that he cannot say exactly what is the matter.

Finally, I did not "castigate as negative" the shared consultation. I stated that "it would be wrong to assume that this new approach is the same as my negative consultation." On the other hand, it is surely important that the shared consultation should be examined to see what effect, if any, it has on patient satisfaction and recovery from illness. Perhaps I could refer Dr Hopayian to the leading article by Professor Bracken on the importance of controlled trials and quote his remark that we choose to ignore, and even to slay, the bearer of bad news when controlled trials tell us what we do not want to hear about many of our diagnostic and therapeutic manoeuvres.

Department of Primary Medical Care,

K B ThомаS

University of Southampton,

Aldermoor Health Centre,

Southampton SOl 6ST

Bracken MB. Clinical trials and the acceptance of uncertainty. $\mathrm{Br}$ Med f 1987;294:1111-2.

\section{Regional secure units: arriving but under} threat

SIR,-Not all of those who "rushed into building" a secure unit had problems of building design or poor siting, as suggested by Dr Peter Richard Snowden (23 May, p 1310).

In Trent we are satisfied with the building, have been committed to a forensic service, and have had no problems in forming links with the courts, probation service, prisons, or district psychiatric services. We did, however, have considerable problems in recruiting nurses and have been forced to operate the unit without adequate medical staff cover.

The regional health authority and the Department of Health and Social Security agreed that the service would be established without detriment to the existing psychiatric services and would require a non-consultant establishment both for training and to provide 24 hour, on the spot availability of medical staff. An establishment of two senior registrars and four registrars was agreed, but only one senior registrar post has been established. This is justified in terms of the manpower freeze and the subsequent Achieving a Balance.

It is not possible to provide an appropriate therapeutic milieu in a totally closed unit without good medical leadership and availability. We cannot alleviate the current shortage of forensic psychiatrists without more and better training posts. There is surely a strong case to depart from the currently inflexible manpower guidelines to ensure that secure units are properly staffed. Without a proper balance of staff secure units could become dangerous and damaging miniasylums.

University of Leicester,

SYDNEY BRANDON

Leicester LE2 7LX

Arnold Lodge Regional Secure Unit

JAMES EARP

\section{Refusal to treat AIDS and HIV positive patients}

SIR,-Dr Raanan Gillon (23 May, p 1332) seems to have failed to address two important issues. Firstly, it is not a question of whether the patient should be treated so much as how much treatment the patient should receive, and, secondly, there is the question of whether the doctor's attitude should be different if he does not have a monopoly of a particular treatment.

Mr Guy (14 February, p 445) has not refused to treat patients with the human immunodeficiency virus when their condition is life threatening, but where should we draw the line? Most doctors would, I believe, treat symptoms that cause discomfort, but even here the issue is not clear cut. What would the General Medical Council's attitude be if a doctor refused to do a haemorrhoidectomy on a patient who was a promiscuous homosexual with the acquired immune deficiency syndrome and wanted treatment only because of uncomfortable anal intercourse? It seems to me that in many cases doctors may and do refuse patients all that they want because of the doctors' own moral stance. For example, would a doctor be acting morally if he treated a torturer who had hurt his arm torturing somebody and who intended to use the arm to go on with the torturing?

The example of a bigoted gay venereologist assumes that the syphilitic surgeon had no one else to go to. If this were so the circumstances would be more extreme and thus the onus would be on the venereologist to examine his views more carefully. Usually there are other doctors available, and it is well within a doctor's rights to refuse to collude with an activity that he considers to be immoral. For example, if a woman smokes cigarettes during pregnancy the doctor may believe that to continue to supervise her antenatal care could be construed as colluding with unnecessary damage to the fetus, which has no choice in the matter. Other doctors may feel differently, and provided there is another doctor who will take her on it seems perfectly in 
order for that doctor to refuse to look after her. The circumstances are different, however, if there are no other doctors easily available-for instance, if he or she is an unopposed general practitioner in a rural area.

D N H GREIG

Health Centre,

Taunton TA1 1JP

\section{Promoting prevention in primary care}

SIR,-With regard to the comments on our paper by $\mathrm{Dr}$ Ann-Louise Kinmonth and colleagues (13 June, p 1551) we accept the lack of absolute proof that the difference in the improvement of recording of cardiovascular disease risk factors in intervention compared with control practices was due entirely to our "facilitator package." We are confident, however, that it made a major contribution for three reasons.

Firstly, although we agree that "case-control" matching of practices is difficult, our matching was done on the basis of considerable knowledge of the practices, and the similarity of baseline data from all intervention and control practices suggests that matching was close. Systematic differences between control and intervention practices were unlikely to have been greater than those between individual practices, whether intervention or control.

Secondly, we agree that the design of our study does not allow distinction between the effects of the initial audit and the "facilitator package," but other evidence suggests that the effects of audit are small compared with that of our intervention. We did not consider it to be justifiable to recruit and audit control practices at the outset without offering them some other intervention.

Thirdly, subsequent application of our model in a large number and variety of practices has produced similar results.

GODFREY FOWLER ELAINE FULLARD

Department of Community Medicine MUIR Gray and General Practice,

University of Oxford,

Oxford OX2 6HE

1 Fleming DM, Lawrence MSTA. The impact of audit on preventive procedures. $\mathrm{Br} \mathrm{Med} \mathrm{f}$ 1983;287:1852-4.

\section{Persistent mesenteric ischaemia in a young} woman

SIR,-The case of mesenteric ischaemia reported by $\operatorname{Dr} \mathrm{N} \mathrm{J}$ Scolding and colleagues (30 May, p 1384) illustrates the difficulty that is often experienced in making this diagnosis. This is often because the definitive investigation, angiography, is not immediately available or is thought to be too invasive in the clinical circumstances. As a result, patients are often subjected to a series of barium or endoscopic studies, which may yield normal or frankly misleading results. With the increasing availability of ultrasound and Doppler equipment this should no longer be such a problem

The normal Doppler signals recorded from the visceral arteries have been well documented.' Pronounced narrowing of the mesenteric arteries produces spectral abnormalities similar to those seen in narrowing of the carotid arteries. ${ }^{2}$ Though the inferior mesenteric artery is only rarely visible on ultrasound examination, the coeliac and superior mesenteric arteries are usually clearly visible. If pulsed Doppler screening is used signals may be obtained from both the coeliac and superior mesenteric arteries. If these are normal (narrow spectrum, peak Doppler shift less than $4 \mathrm{kHz}$ ) mesenteric ischaemia is unlikely. If one of the traces is abnormal or if a vessel is found to be occluded then mesenteric ischaemia is quite likely, and angiography is indicated to visualise all the mesenteric arteries. In equivocal cases a test meal and further Doppler screening after 15 minutes may be useful.

We have now correlated the results of duplex Doppler ultrasound examination with those of angiography in six patients with symptoms suggestive of mesenteric ischaemia. The five patients with severe mesenteric arterial narrowing or occlusion and one patient with normal arteries, as shown by angiography, were all correctly identified by duplex Doppler screening.

Duplex Doppler screening seems to be a safe and accurate method for diagnosing mesenteric ischaemia. The wide availability of this technique should reduce the number of late diagnoses and also the number of repeated endoscopies and barium studies to which these patients are subjected.

We should also remember that atherosclerosis is becoming common in women who smoke and we should not be surprised when they develop symptoms related to it.

Bristol Royal Hospital

G G HARTNELL

for Sick Children,

Bristol BS2 8BJ

1 Taylor KJW, Burns PN, Woodcock JP, Wells PNT. Blood flow in deep abdominal vessels: ultrasonic pulsed Doppler analysis. Radiology 1985;154:487-93.

2 Hartnell GG, Gibson RN. Doppler ultrasound in the diagnosis of mesenteric ischaemia. Gastrointest Radiol (in press).

\section{Health and efficiency}

SIR,-Sir Bryan Thwaites deserves Dr Richard Smith's praise (6 June, $p$ 1438) for his public candour about the inevitability of rationing in the National Health Service, and especially for illustrating what this means with specific cases. The worldwide financial crisis in health care, however, points equally to another lesson: there is now a tough minded, economic case for health promotion.

Perhaps in hope, perhaps in naivety, all parties to the present debate on NHS financing have underestimated the seriousness of the problem The gap between Britain's need for health care and our resources to provide it is massive, and the deficit will not be bridged by increases in efficiency, technical advances in curative medicine, or marginal growth in public expenditure. We cannot go on dealing with health problems as we have done so far: with high cost, high technology, chemotherapeutic, hospital based treatment by expensively trained professionals. We must change, as it is financially impossible to carry on as before.

Once we acknowledge solemnly, as Sir Bryan has done, that we cannot afford to deal with health problems after they have arisen then on economic as well as moral grounds we must prevent such problems from developing in the first place. Until now disease prevention and health promotion have been seen as supplementary luxuries, programmes to develop once adequate curative services are in place. That is a financial as well as a physiologica fantasy. We now recognise that we will never increase the supply of care sufficiently, and, therefore, we must lower the demand for it. This means more than negative rationing. We must act positively to reduce the real incidence of disease.

Dr Smith pointed out two consequences of taking health promotion seriously: reallocating ministerial responsibilities and reallocating public expenditure. These are serious challenges for the new Secretary of State. He must show the same zeal in eliminating preventable disease as in eliminating inefficiency. A secure financial future for the NHS entails more than controlling expenditure, it requires the control of disease.

\section{King's Fund Institute,}

J T WINKLER

London NW1 7NF Lond

\section{Vacancy advertisements}

SIR,-Dr Christopher Side (16 May, p 1265) discussed the unsatisfactory nature of most advertisements for new or replacement partners for practices. Just how little information is contained in many such advertisements is further highlighted by the fact that when these partnership advertisements are compared with those seeking general practitioner trainees more useful information seems to be given to prospective trainees than to prospective partners. By adapting a system of analysis of partnership advertisements described by Higson, ${ }^{1}$ I evaluated whether the impression is well founded.

Advertisements for 40 partnership and 40 general practitioner traineeship posts were analysed, with vacancies advertised by family practitioner committees being excluded. Information that might be useful to an applicant was grouped into 14 categories and, for each advertisement, scored 0 if no information was given, 1 if limited or vague information was given, and 2 if specific information was supplied. The 14 categories were: site of practice, practice premises, access to other facilities, size of practice, attached staff, diagnostic equipment available, date of vacancy, names of partners, telephone number, address, information about practice locality, and requirements of prospective applicants (for example, "must have family planning certificate"). The remaining two categories differed for partnership and trainee advertisements because of obvious differences in the nature of the post; these were: statement of salary/share and whether full or part time (for partnerships) and length of vacancy and day release course details (for traineeships). The total score for each advertisement was calculated and the scores for the two groups compared.

Some differences between the scores for each group were very obvious. For instance, a full practice address was stated in every traineeship advertisement whereas 11 partnership advertisements gave either the BMA services address or a box number, and over half of the partnership advertisements gave no information about attached staff, compared with 15 of the traineeship advertisements.

The mean score for the partnership advertisements was 10.0 (SD 4.0) compared with $14.6(2.4)$ for the traineeship advertisements. This difference proved to be significant when a simple difference of two means test was applied $(p<0.001)$.

Significantly more information is to be found in advertisements seeking a trainee than in those advertising for a future partner. Presumably, this is a result of market forces (there being a glut of potential partners but a scarcity of potential trainees in relation to numbers of vacancies), but it has resulted in the rather ludicrous situation of prospective trainees, who will be with the practice for a year at most, being given more information in advertisements than prospective partners, who may be with the practice for 30 years or more.

\section{Bristol BS10 5SQ}

MARTIN BELL

Higson N. Do advertisements help in the appointment of a new partner? Br Med f 1985;290:35-6. 